\title{
Respostas Morfogênicas e Estruturais de Panicum maximum cv. Mombaça sob Diferentes Níveis de Adubação Nitrogenada e Alturas de Corte ${ }^{1}$
}

\author{
Américo Fróes Garcez Neto ${ }^{2}$, Domicio do Nascimento Junior ${ }^{3}$, Adair José Regazzi ${ }^{4}$, \\ Dilermando Miranda da Fonseca ${ }^{5}$, Paulo Roberto Mosquim ${ }^{6}$, Kátia Fernanda Gobbi ${ }^{7}$
}

RESUMO - As características morfogênicas e estruturais da gramínea Panicum maximum cv. Mombaça foram estudadas em função de diferentes níveis de suprimento de nitrogênio e alturas de corte. O estudo foi conduzido em casa de vegetação, sendo avaliadas quatro doses de nitrogênio $\left(0,50,100\right.$ e $\left.200 \mathrm{mg} / \mathrm{dm}^{3}\right)$ e três alturas de corte $(5,10$ e $20 \mathrm{~cm})$. As avaliações morfogênicas englobaram as taxas de aparecimento e alongamento de folhas, filocrono e duração de vida da folha. As estruturais avaliaram o número de folhas, o número de perfilhos e o comprimento final da lâmina foliar. Foi bastante expressiva a resposta da gramínea quanto às suas características morfogênicas em relação ao suprimento de nitrogênio na rebrotação, caracterizando o importante papel do nitrogênio como ferramenta para manipular a estrutura da planta. Todas as variáveis no estudo responderam positivamente ao suprimento de nitrogênio, com exceção do filocrono, que foi reduzido pelo efeito nutricional. As diferenças nas alturas de corte foram significativas para caracterização da duração de vida da folha, assim como para o comprimento de folhas e número de folhas verdes por perfilho. As taxas de alongamento e aparecimento de folhas foram incrementadas em até 133 e 104\%, respectivamente, pelo aumento na disponibilidade de nitrogênio. A relação entre ambas as variáveis foi determinante na caracterização das principais mudanças vegetativas observadas. A grande resposta nas características morfogênicas do cultivar estudado constitui eficiente meio para manipular a estrutura do dossel, possibilitando melhor alocação dos recursos produtivos no processo de crescimento e desenvolvimento da planta.

Palavras-chave: adubação, altura de corte, estrutura, folhas, morfogênese, perfilhos

\section{Morphogenetic and Structural Responses of Panicum maximum cv. Mombaça on Different Levels of Nitrogen Fertilization and Cutting Regimes}

\begin{abstract}
The morphogenetic and structural characteristics of Panicum maximum cv. Mombaça were evaluated in response to different levels of nitrogen supply and cutting regimes. The study was conducted in a glasshouse with natural conditions of light and temperature. Treatments corresponded to four levels of nitrogen supply $\left(0,50,100\right.$ and $\left.200 \mathrm{mg} / \mathrm{dm}^{3}\right)$ and three cutting heights $(5,10$ and $20 \mathrm{~cm}$ ). The morphogenetic evaluations included leaf appearance and elongation rate, phyllochron and leaf lifespan. The structural measurements were: number of leaves, number of tillers and leaf lamina length of fully expanded leaves. The morphogenetic responses were affected by nitrogen supply during regrowth, highlighting the importance of that nutrient for manipulating sward structure. All variables responded positively to nitrogen supply, except phyllochron. Cutting height had a significant effect on leaf lifespan, leaf lamina length of fully expanded leaves and number of green leaves per tiller. Leaf appearance and elongation rate per tiller were increased in 133 and 104\%, respectively, by nitrogen supply. The relationship between both group of variables was determinant for the characterization of the main vegetative changes on plants. The responses observed on morphogenetic characteristics comprise an efficient attribute to manipulate canopy structure, allowing improved allocation of productive resources to growth and developmental processes.
\end{abstract}

Key Words: cutting height, fertilization, leaves, morphogenesis, structure, tillers

\section{Introdução}

A produção animal com base em pastagens pode ser visualizada, basicamente, como um processo de três estádios: crescimento da planta forrageira, utilização da forragem produzida e sua conversão em produto animal (Hodgson, 1990). A produção forrageira, como resultado dos processos de crescimento e desenvolvimento, pode ter sua eficiência substancialmente melhorada pelo aumento do uso de fertilizantes, principalmente do nitrogênio, através do expressivo aumento no fluxo de tecidos (Simon \&

\footnotetext{
1 Parte da dissertação do primeiro autor no curso de Mestrado em Forragicultura e Pastagens, Departamento de Zootecnia, UFV. Viçosa, MG, CEP: 36571-000.

2 Zootecnista MSc., Bolsista do CNPq, Estudante do Departamento de Zootecnia, UFV, Viçosa, MG. E.mail:americo.garcez@bol.com.br

3 Professor PhD., Departamento de Zootecnia, UFV, Viçosa, MG. E.mail: domicion@ufv.br

4 Professor DS., Departamento de Informática, UFV, Viçosa, MG. E.mail: adairreg@ufv.br

5 Professor DS., Departamento de Zootecnia, UFV, Viçosa, MG. E.mail: dfonseca@ufv.br

6 Professor DS., Departamento de Biologia, UFV, Viçosa, MG. E.mail: pmosquim@ufv.br

7 Estudante de Zootecnia, Bolsista de Iniciação Científica do CNPq, Departamento de Zootecnia, UFV, Viçosa, MG.
} 
Lemaire, 1987; Duru \& Ducrocq, 2000a).

O sucesso na utilização de pastagens depende não só da disponibilidade de nutrientes ou da escolha da planta forrageira a ser utilizada, como também da compreensão dos mecanismos morfofisiológicos e de sua interação com o ambiente, ponto fundamental para suportar tanto o crescimento quanto a manutenção da capacidade produtiva da pastagem. Os estudos de fluxo de tecidos através de processos morfogênicos vêm se constituindo em importante ferramenta para avaliação da dinâmica de folhas e perfilhos em comunidade de plantas forrageiras.

Numa pastagem em crescimento vegetativo, no qual apenas folhas são produzidas, a morfogênese pode ser descrita por três características básicas: taxa de aparecimento de folhas, taxa de alongamento de folhas e duração de vida da folha. A combinação dessas variáveis morfogênicas básicas determina as principais características estruturais das pastagens: tamanho da folha, densidade populacional de perfilhos e número de folhas vivas por perfilho. A taxa de aparecimento de folhas exerce papel central na morfogênese por causa de sua influência direta sobre cada um dos três componentes da estrutura da pastagem (Lemaire \& Chapman, 1996).

Taxas de crescimento individuais podem ser controladas, basicamente, por dois fatores principais: o suprimento de energia para fotossíntese, que reflete o tamanho e a eficiência fotossintética do dossel, e o número e a atividade de pontos de crescimento, caracterizados pelo potencial de perfilhamento (perfilhos $/ \mathrm{m}^{2}$ ) (Hodgson, 1990).

A produção de novos perfilhos é, normalmente, um processo contínuo, o qual pode ser acelerado pela desfolhação da planta e consequiente melhoria do ambiente luminoso na base do dossel. Perfilhos individuais têm duração de vida limitada e variável em função de fatores bióticos e abióticos, de modo que a sua população pode ser mantida por uma contínua reposição dos perfilhos mortos. Esse comportamento é ponto-chave para a perenidade das gramíneas.

O conjunto de processos envolvendo as transformações da planta diante de fatores bióticos e abióticos, ao longo do tempo, caracteriza a resposta fenotípica como resultado de mudanças nas características morfogênicas. Lemaire \& Agnusdei (1999) caracterizaram essas mudanças como um processo progressivo e irreversível, altamente regulado, em que qualquer mudança estrutural resulta em respostas morfogênicas das plantas e nova estrutura do dossel.
Significativo fluxo de carbono para os meristemas apicais após a desfolhação tem sido caracterizado como uma importante resposta adaptativa da planta para sua recuperação. Esse fluxo, no entanto, parece ser fortemente influenciado pelos processos de absorção, partição e reciclagem de nitrogênio. A utilização de carbono em atividades meristemáticas associadas a processos morfogênicos tem se mostrado bastante dependente de uma adequada nutrição nitrogenada (Gastal et al., 1992).

Em virtude dessa constatada associação entre $\mathrm{C}$ e $\mathrm{N}$ na planta e do papel do $\mathrm{N}$ em várias características morfogênicas envolvendo a dinâmica de folhas e perfilhos, fazem-se necessários novos estudos de avaliação em gramíneas forrageiras quanto ao seu potencial de resposta à adubação nitrogenada.

Este trabalho foi proposto com o objetivo de avaliar em que magnitude o fator nutricional, por meio do suprimento de nitrogênio, e os regimes de corte, através de diferentes alturas de corte, afetam as características morfogênicas e estruturais da gramínea Panicum maximum cv. Mombaça.

\section{Material e Métodos}

\section{Delineamento experimental}

O estudo foi conduzido em casa de vegetação da Unidade de Crescimento de Plantas, campus da Universidade Federal de Viçosa - Minas Gerais, com o objetivo de avaliar as respostas morfogênicas e estruturais da gramínea Panicum maximum cv. Mombaça em rebrotação. As plantas foram cultivadas em vasos plásticos com $11 \mathrm{dm}^{3}$, sob regime de luz e temperatura natural e utilizando-se solo da região (Latossolo Vermelho-Amarelo de textura franco-argilosa).

Foram avaliadas quatro doses de nitrogênio e três alturas de corte, constituindo um fatorial $4 \times 3$, no delineamento em blocos casualizados completos, com três repetições, totalizando 36 vasos ou unidades experimentais. As doses de nitrogênio testadas foram: testemunha (sem adubação), 50, 100 e $200 \mathrm{mg} / \mathrm{dm}^{3}$, e as alturas de corte: 5,10 e $20 \mathrm{~cm}$.

A semeadura foi feita no dia 12.2.2000, em caixas plásticas contendo areia. Em 27.2.2000, transplantaram-se para os vasos entre 8 e 10 plântulas, de modo que no momento do desbaste fosse possível a obtenção de cinco plântulas por unidade experimental.

No dia 26.3.2000, foi feito o corte de uniformização, nas alturas de 5,10 e $20 \mathrm{~cm}$, nos respectivos tratamentos.

\section{R. Bras. Zootec., v.31, n.5, p.1890-1900, 2002}


As doses de nitrogênio foram parceladas em quatro aplicações, a intervalos de 13 dias, sendo a primeira aplicação feita no dia seguinte ao corte de uniformização. $\mathrm{O}$ fertilizante nitrogenado utilizado nos tratamentos foi o sulfato de amônio, diluído em água e aplicado sobre o solo. O volume de solução por aplicação foi de $25 \mathrm{~mL}$ por vaso.

Avaliações

Para as avaliações das características morfogênicas e estruturais, foram marcados três perfilhos por vaso com anéis plásticos coloridos. Os perfilhos identificados eram mensurados três vezes por semana, durante os 48 dias de rebrotação.

Registrou-se o dia do aparecimento do ápice foliar, o dia da exposição da lígula, o comprimento do pseudocolmo, o comprimento da lâmina foliar expandida, o comprimento da lâmina foliar em expansão, o número de folhas por perfilho e o número de perfilhos por planta.

Tanto as medidas morfogênicas como as estruturais, que se encontram ajustadas à escala temporal, foram, de forma análoga, relacionadas à escala de tempo térmico em unidades térmicas de crescimento, possibilitando uma interpretação mais ampla dos fenômenos encontrados (Bonhomme, 2000).

Para isso, foi utilizado o conjunto de equações proposto por Ometto (1981), em que as unidades térmicas são definidas como graus-dia (GD) de crescimento. $\mathrm{Na}$ equação para estimar os graus-dia é utilizada a temperatura mínima basal da planta. Essa temperatura foi estimada, para o Panicum maximum cv. Mombaça, em um ensaio paralelo, em $13,8^{\circ} \mathrm{C}$. Em todo o período de rebrotação foram acumulados 483,04 GD.

As temperaturas mínima e máxima registradas foram de 10,4 e $35,2^{\circ} \mathrm{C}$, respectivamente, e a temperatura média do período foi de $21,7^{\circ} \mathrm{C}$.

\section{Variáveis morfogênicas e estruturais}

As taxas de alongamento e aparecimento de folhas foram calculadas dividindo-se o comprimento acumulado de folhas e o número total de folhas no perfilho, respectivamente, pelo período de rebrotação. O cálculo era efetuado para cada perfilho marcado, de modo que o valor final constituía a média de três perfilhos por vaso. A duração de vida da folha foi estimada considerando-se o tempo entre o aparecimento do ápice foliar e o primeiro sinal de senescência da lâmina. O filocrono foi estimado como o inverso da taxa de aparecimento de folhas (Skinner \& Nelson, 1995).
O número de folhas verdes por perfilho foi determinado como a fração de folhas totais que não apresentavam qualquer sinal de senescência. O número de perfilhos por planta era contabilizado nas plantas em que os perfilhos estavam marcados. O tamanho final da folha foi determinado pelo comprimento entre o ápice foliar e a lígula da mesma folha.

\section{Análise estatística}

As análises estatísticas foram feitas usando os procedimentos de modelos lineares gerais (GLM) e de regressão (REG) do Sistema para Análises Estatísticas SAS (1990). Uma vez que os fatores nitrogênio e altura são quantitativos, seus efeitos foram avaliados por meio de análise de regressão.

\section{Resultados e Discussão}

\section{Crescimento e desenvolvimento de folhas}

Não foi observado efeito significativo de interação entre doses de nitrogênio e alturas de corte, ficando a significância limitada aos fatores isolados. O nitrogênio foi o fator com significância estatística mais evidente entre as respostas avaliadas.

\section{Taxa de aparecimento de folhas e filocrono}

O efeito do suprimento de nitrogênio sobre a taxa de aparecimento de folhas $\left(\mathrm{TA}_{\mathrm{P}} \mathrm{F}\right)$ foi significativo $(\mathrm{P}<0,10)$, promovendo expressivo aumento no número de folhas por perfilho no período. A equação de regressão que melhor se ajustou aos dados está apresentada na Figura 1.

A discussão do efeito nutricional, particularmente do nitrogênio, sobre a $\mathrm{TA}_{\mathrm{P}} \mathrm{F}$, insistentemente tem sugerido respostas mais conservadoras que as encontradas no presente estudo (Langer, 1974; Cruz \& Boval, 1999). Outros trabalhos, todavia, já demonstraram o significativo papel do nitrogênio sobre a mesma variável (Thomas, 1983; Longnecker et al., 1993; Duru \& Ducrocq, 2000a). Longnecker et al. (1993) argumentaram que a discrepância entre os estudos pode ser devida aos diferentes níveis de estresse nitrogenado aplicados às plantas.

A TA $\mathrm{P} F$ não foi influenciada pela altura de corte $(\mathrm{P}>0,10)$. Alguns trabalhos que mostram o efeito de alturas de corte ou pastejo sobre a $\mathrm{TA}_{\mathrm{P}} \mathrm{F}$, normalmente, são fundamentados na altura de bainhas remanescentes. Foi constatado que o maior comprimento da bainha conduz a planta a uma menor $\mathrm{TA}_{\mathrm{P}} \mathrm{F}$ (Skinner \& Nelson, 1995; Duru \& Ducrocq, 2000a). Esse comportamento se deve ao fato de as folhas surgirem

\section{R. Bras. Zootec., v.31, n.5, p.1890-1900, 2002}




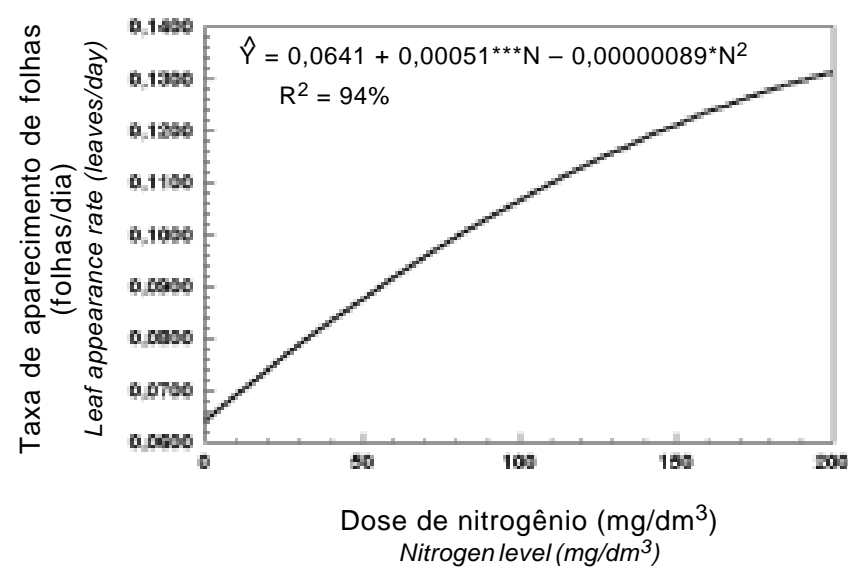

Figura 1 - Taxa de aparecimento de folhas, expressa em dias, de capim Mombaça em função do suprimento de nitrogênio $\left(0,50,100\right.$ e $\left.200 \mathrm{mg} / \mathrm{dm}^{3}\right)$; significativo a $1 \%\left(^{* *}\right)$ e $10 \%\left({ }^{*}\right)$.

Figure 1 - Leaf appearance rate, expressed in days, of Panicum maximum $\mathrm{cv}$. Mombaça in response to nitrogen supply (0, 50, 100 and $\left.200 \mathrm{mg} / \mathrm{dm}^{3}\right)$; significant at $1 \%\left({ }^{* *}\right)$ and $10 \%\left({ }^{*}\right)$.

sucessivamente em níveis de inserção cada vez mais altos e ao processo natural de alongamento da bainha. Desse modo, a folha percorre um maior trajeto entre seu ponto de conexão com o meristema e a extremidade do pseudocolmo formado pelas bainhas das folhas mais velhas.

A não-significância da altura de corte sobre a $\mathrm{TA}_{\mathrm{P}} \mathrm{F}$ pode ser devida à reduzida diferença entre alturas adotada nos tratamentos. Com alturas mais contrastantes, haveria maior trajeto a ser percorrido pela folha no interior do pseudocolmo. Como as folhas sucessivas se alongam a taxas equivalentes, a $\mathrm{TA}_{\mathrm{P}} \mathrm{F}$ seria diminuída com o aumento da altura.

O papel do suprimento de nitrogênio sobre a $\mathrm{TA}_{\mathrm{P}} \mathrm{F}$ pode ser analisado como resultado da combinação de uma série de fatores, como altura de bainha, alongamento foliar e temperatura (Duru \& Ducrocq, 2000ab), agindo simultaneamente. A taxa à qual as folhas se alongam age alterando o padrão de aparecimento de lâminas foliares. Isso ocorre em função da modificação do tempo gasto pela folha, desde sua iniciação no meristema até o seu aparecimento acima do pseudocolmo formado pelas folhas mais velhas.

Observa-se, assim, que não só o comprimento da bainha, mas particularmente a taxa de alongamento de folhas, pode explicar, no sentido mais amplo, o com- portamento da $\mathrm{TA}_{\mathrm{P}} \mathrm{F}$ em relação aos tratamentos adotados. A taxa de alongamento, ao responder ao suprimento de $\mathrm{N}$, seria, então, o principal agente modificador da $\mathrm{TA}_{\mathrm{P}} \mathrm{F}$. Folhas sucessivas aparecendo em níveis de inserção muito próximos, mas sob elevadas taxas de alongamento, suportadas pelo suprimento adicional de $\mathrm{N}$, estabeleceriam maior $\mathrm{TA}_{\mathrm{P}} \mathrm{F}$.

$\mathrm{O}$ filocrono, calculado como o inverso da $\mathrm{TA}_{\mathrm{P}} \mathrm{F}$, foi significativamente $(\mathrm{P}<0,01)$ afetado pelo suprimento de nitrogênio, apresentando resposta quadrática para as doses de $\mathrm{N}$ estudadas

Os valores encontrados para as quatro doses de nitrogênio $\left(0,50,100\right.$ e $\left.200 \mathrm{mg} / \mathrm{dm}^{3}\right)$, de acordo com a equação ajustada, foram, respectivamente, de 16, 12,9 e 8 dias/folha, o que corresponde a 173, 125, 94 e 80 graus-dia/folha.

Além de atuar sobre o filocrono, aumentando a produção de novas células, o $\mathrm{N}$ pode ainda caracterizar a variável através de mudanças provocadas na taxa de alongamento de folhas. Esse efeito pode ser tanto maior quanto menor for a significância do fator nitrogênio no processo de alongamento do colmo. Esse comportamento pode ser explicado pelo fato da folha poder ser exposta acima da bainha das folhas mais velhas, percorrendo praticamente um mesmo percurso, porém a maiores taxas de alongamento. $\mathrm{O}$ comportamento do filocrono em resposta às doses de nitrogênio é mostrado na Figura 2.

\section{Taxa de alongamento de folhas}

A taxa de alongamento de folhas foi significativamente superior $(\mathrm{P}<0,10)$ para os tratamentos que receberam maior suprimento de nitrogênio, não havendo efeito significativo de altura de corte e de interação entre os fatores (Figura 3).

Outros trabalhos que avaliaram o efeito do nitrogênio sobre a taxa de alongamento de folhas $\left(\mathrm{TA}_{\mathrm{L}} \mathrm{F}\right)$ revelaram resultados semelhantes aos encontrados no presente experimento (Volenec \& Nelson, 1983; Gastal \& Nelson, 1994). Em um estudo com Festuca arundinacea foi observado que a $\mathrm{TA}_{\mathrm{L}} \mathrm{F}$ foi aumentada em $140 \%$ quando o suprimento de nitrogênio passou de 22 para $336 \mathrm{~kg} / \mathrm{ha}$, comportamento esse que foi atribuído muito mais ao expressivo aumento no número de células que ao possível aumento no comprimento final da célula ou na sua taxa de alongamento (Volenec \& Nelson, 1984).

Mazzanti et al. (1994) também encontraram efeitos significativos do nitrogênio sobre a $\mathrm{TA}_{\mathrm{L}} \mathrm{F}$ quando a dose de nitrogênio passou de 40 para $90 \mathrm{~kg} / \mathrm{ha}$, aplica- 

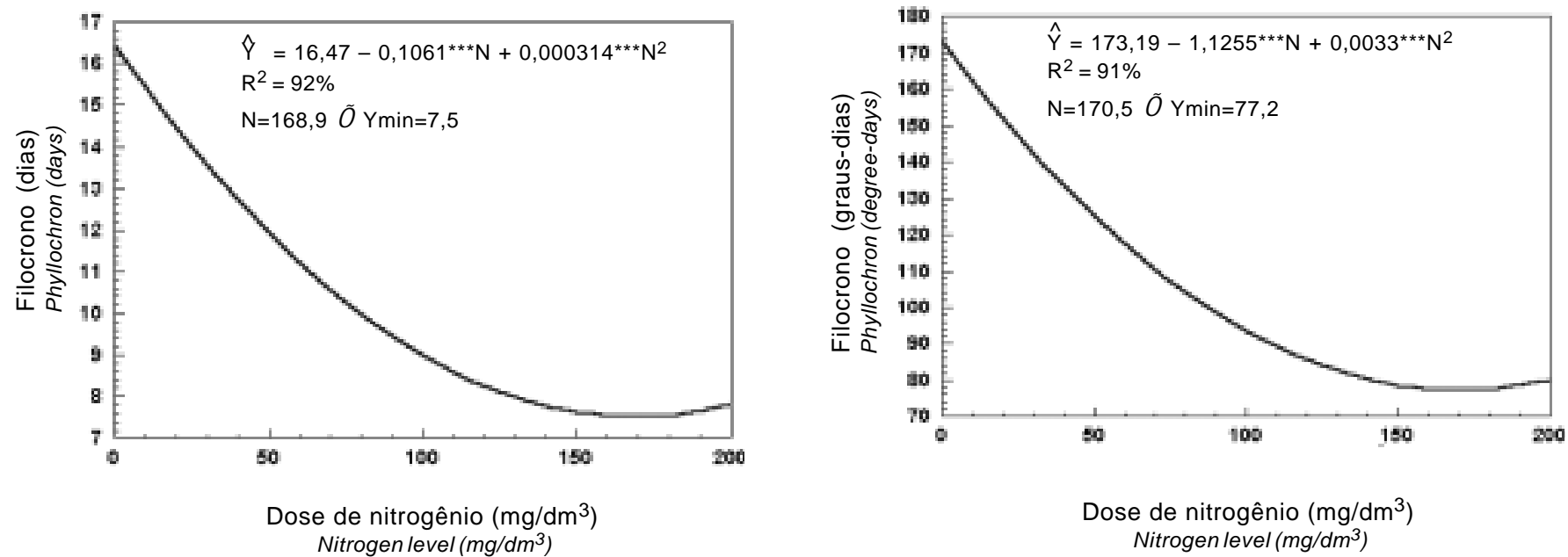

Figura 2 - Filocrono, expresso em dias e graus-dia de capim Mombaça, em função do suprimento de nitrogênio; significativo a $1 \%\left(^{* * *}\right)$.

Figure 2 - Phyllochron, expressed in days and degree-days of Panicum maximum cv. Mombaça, in response to nitrogen supply; significant at $1 \%\left({ }^{* \star *}\right)$.

dos a cada 45 dias. Foi obtido aumento médio de 15 a $28 \%$ na $\mathrm{TA}_{\mathrm{L}} \mathrm{F}$ dos perfilhos protegidos, ao passo que os perfilhos pastejados não mostraram qualquer resposta significativa à fertilização. Em dois dos três anos de estudo, Duru \& Ducrocq (2000a) observaram aumento significativo na $\mathrm{TA}_{\mathrm{L}} \mathrm{F}$ (76 a $80 \%$ ) quando o suprimento de nitrogênio variou de 0 para $120 \mathrm{~kg} / \mathrm{ha}$, sem que houvesse efeito dos regimes de corte.

Considerando a ausência de nitrogênio como testemunha, as doses de 50,100 e $200 \mathrm{mg}$ de $\mathrm{N} / \mathrm{dm}^{3}$ conduziram a um aumento médio de 52,92 e $133 \%$ na $\mathrm{TA}_{\mathrm{L}} \mathrm{F}$, ratificando o significativo papel desse nutriente no comportamento dessa variável (Figura 3). Gomide (1997), utilizando uma dose de $150 \mathrm{mg}$ de $\mathrm{N} / \mathrm{dm}^{3} \mathrm{e}$ avaliando o perfilho principal durante a rebrotação em quatro cultivares de Panicum maximum, encontrou uma $\mathrm{TA}_{\mathrm{L}} \mathrm{F}$ média de $66,57 \mathrm{~mm} /$ dia. O cultivar Mombaça foi um dos que apresentaram menor TALF. Projetandoa mesma dose de nitrogênio $\left(150 \mathrm{mg} \mathrm{de} \mathrm{N} / \mathrm{dm}^{3}\right)$ para o presente estudo, de acordo com o modelo ajustado, seria estimada uma $\mathrm{TA}_{\mathrm{L}} \mathrm{F}$ de $54 \mathrm{~mm} / \mathrm{dia}$, provavelmente um valor muito próximo ao encontrado por Gomide (1997).

De forma geral, todos os resultados apresentados vêm concordando com a sugestão de que o alongamento foliar é, realmente, influenciado pelo suprimento de nitrogênio. Esse comportamento pode ser ratificado pelo estudo de deposição de nutrientes nas zonas de alongamento e divisão celular das folhas (Skinner \& Nelson, 1995).

\section{Duração de vida da folha}

A duração de vida da folha (DVF) foi aumentada significativamente $(\mathrm{P}<0,05)$ com o aumento da altura de corte e com a adubação nitrogenada, mas sem que houvesse efeito da interação entre os fatores. Duru \& Ducrocq (2000a) constataram efeito significativo tanto dos regimes de corte sobre a duração de vida da

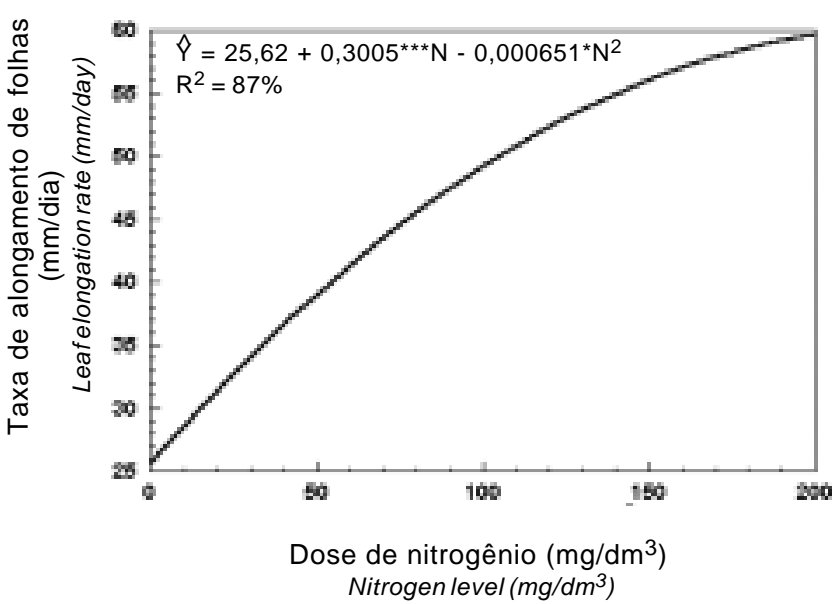

Figura 3 - Taxa de alongamento de folhas, expressa em dias, de capim Mombaça em função do suprimento de N; significativo a $1 \%\left(^{* * *}\right)$ e $10 \%\left(^{*}\right)$.

Figure 3 - Leaf elongation rate, expressed in days, of Panicum maximum $\mathrm{cv}$. Mombaça in response to nitrogen supply, significant at $1 \%^{\left({ }^{* *}\right)}$ and $10 \%\left({ }^{*}\right)$.

\section{R. Bras. Zootec., v.31, n.5, p.1890-1900, 2002}


folha (duas estações de crescimento) como dos regimes de corte e do suprimento de nitrogênio (uma estação de crescimento), sem que houvesse interação entre os fatores.

A estimativa da duração média de vida da folha, considerando as alturas de corte e as doses de $\mathrm{N}$, variou de 31 dias (311 graus-dia) para o tratamento em que não havia suprimento de $\mathrm{N}$ e o corte era efetuado a $5 \mathrm{~cm}$ até quase 48 dias (480 graus-dia) para o tratamento em que o suprimento de $\mathrm{N}$ chegou a $200 \mathrm{mg} / \mathrm{dm} 3$ e a altura de corte era de $20 \mathrm{~cm}$. A média, considerando todos os tratamentos, foi de 38 dias, ou 386 graus-dia.

$\mathrm{O}$ mecanismo de ação do $\mathrm{N}$ no prolongamento da vida da folha pode estar associado à manutenção de maior capacidade fotossintética por períodos mais longos, sem que haja remobilização interna significativa de nitrogênio das folhas mais velhas. Esse comportamento pode ser mais bem compreendido se analisado em conjunto com o processo de senescência das folhas. Uma vez estabelecida a senescência, boa parte do $\mathrm{N}$ é remobilizada para as folhas mais novas (Lemaire \& Culleton, 1989). Essa mobilização pode contribuir de forma significativa para a redução da atividade fotossintética de folhas mais velhas.

$\mathrm{O}$ aumento observado na DVF em função da elevação da altura de corte pode ser explicado por meio do processo morfológico de desenvolvimento do órgão foliar. Se o corte for feito a uma altura maior e a taxa de alongamento não variar com a altura deste, como foi verificado, é possível que a lâmina, além de ter sua duração de alongamento aumentada, atrasando o início da senescência, tenha sua duração de vida estendida, caracterizando, portanto, o papel da altura de corte na expressão da variável no presente estudo.

Na Tabela 1 são apresentadas as médias de duração de vida da folha, em função dos tratamentos estudados.

Como pode ser observado na Tabela 1 , o efeito do nitrogênio teve comportamento diferenciado em relação à duração de vida da folha nas diferentes alturas. O suprimento de nitrogênio praticamente só aumentou a DVF nos cortes a 5 e $10 \mathrm{~cm}$, sendo mínima a variação na DVF no corte a $20 \mathrm{~cm}$. Observa-se maior magnitude na resposta da variável quando a variação ocorre nas alturas de corte do que no suprimento de nitrogênio, apesar de ambos serem estatisticamente significativos (Figura 4).
Tabela 1 - Médias de duração (dias) de vida da folha de capim Mombaça em função do suprimento de nitrogênio e das alturas de corte

Table 1 - Mean leaf lifespan (days) of Panicum maximum cv. Mombaça in response to nitrogen supply and cutting height

\begin{tabular}{|c|c|c|c|c|c|}
\hline \multirow[t]{2}{*}{$\begin{array}{l}\text { Altura de corte } \\
(\mathrm{cm}) \\
\text { Cutting height } \\
(\mathrm{cm})\end{array}$} & \multicolumn{4}{|c|}{$\begin{array}{c}\text { Dose de nitrogênio } \\
\left(\mathrm{mg} / \mathrm{dm}^{3}\right) \\
\text { Nitrogen level } \\
\left(\mathrm{mg} / \mathrm{dm}^{3}\right)\end{array}$} & \multirow[t]{2}{*}{$\begin{array}{c}\text { Médias } \\
\text { Means }\end{array}$} \\
\hline & 0 & 50 & 100 & 200 & \\
\hline 5 & 33 & 29 & 33 & 35 & 32 \\
\hline 10 & 34 & 38 & 36 & 44 & 38 \\
\hline 20 & 45 & 43 & 45 & 46 & 45 \\
\hline $\begin{array}{l}\text { Médias } \\
\text { Means }\end{array}$ & 37 & 36 & 38 & 42 & \\
\hline
\end{tabular}

\section{Comprimento final da folha}

$\mathrm{Na}$ avaliação do comprimento final da lâmina foliar em relação aos fatores estudados, tanto o nitrogênio $(\mathrm{P}<0,10)$ como as alturas de corte $(\mathrm{P}<0,05)$ mostraram efeito significativo (Figura 5 ). Na equação ajustada, ambos os fatores influenciaram o aumento do comprimento da lâmina, no entanto as diferentes alturas de corte proporcionaram maior amplitude de variação em relação à variável (Tabela 2).

Para o comprimento da lâmina, os resultados encontrados se mostraram de acordo com os obtidos por Duru \& Ducrocq (2000a), em todas as estações

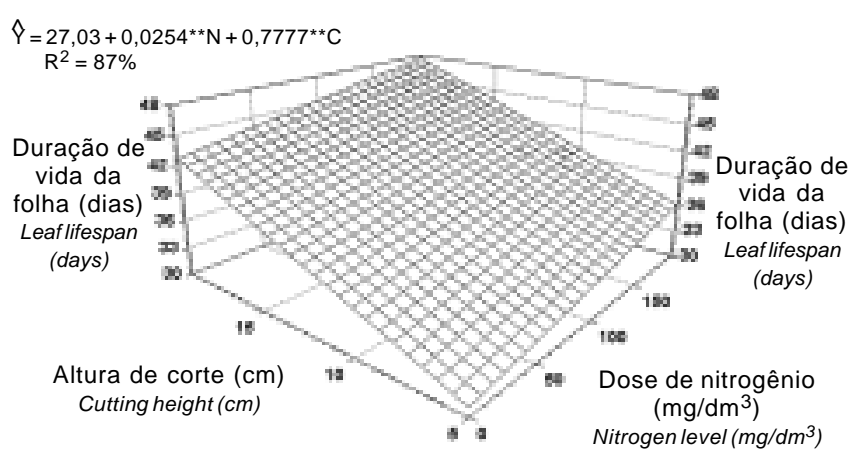

Figura 4 - Duração de vida da folha, expressa em dias, de capim Mombaça em função do suprimento de nitrogênio e das alturas de corte; significativo a $5 \%\left({ }^{* *}\right)$.

Figure 4 - Leaf lifespan, expressed in days, of Panicum maximum $\mathrm{cv}$. Mombaça in response to nitrogen supply and cutting height; significant at $5 \%\left(^{* *}\right)$. 
$\hat{\mathrm{Y}}=34,64+0,0897^{\star * *} \mathrm{~N}+0,8109^{* *} \mathrm{C}-0,0003^{*} \mathrm{~N}^{2}$

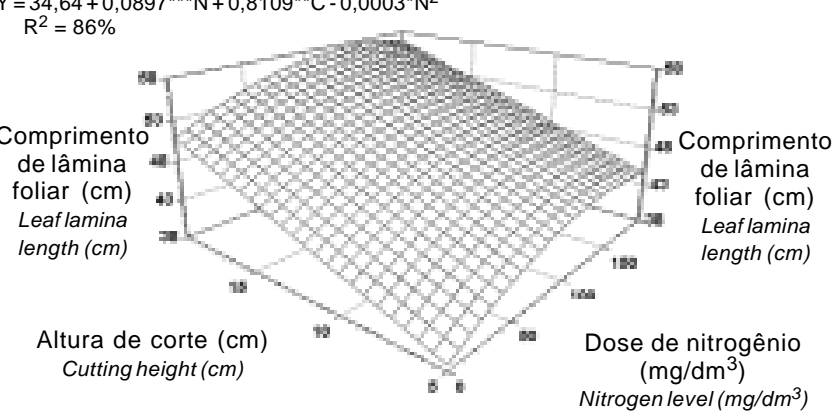

Figura 5 - Comprimento médio de lâmina foliar do capim Mombaça por perfilho em função do suprimento de $\mathrm{N}$ e das alturas de corte; significativo a $1 \%\left(^{* * *}\right), 5 \%\left(^{* *}\right)$ e $10 \%\left(^{*}\right)$.

Figure 5 - Means of leaf lamina length of Panicum maximum cv. Mombaça per tiller in response to nitrogen supply and cutting height; significant at $1 \%\left({ }^{* * *}\right)$, $5 \%\left(^{* *}\right.$ ) and $10 \%\left({ }^{*}\right)$.

de crescimento por eles avaliadas, ratificando a significância dos dois fatores, sem que houvesse interação entre eles. Foi observado, no presente estudo, que a redução do comprimento da bainha por meio de diferentes alturas de corte reduziu o comprimento da lâmina; esse comportamento foi similar ao encontrado por Wilson \& Laidlaw (1985). No entanto, quando as condições para o crescimento são favoráveis e constantes, a divisão celularé também favorecida, de modo que é possível obter lâminas maiores para um mesmo comprimento de bainha.

O aumento no tamanho de lâmina em relação aos tratamentos pode ser explicado pelo efeito simultâneo do nitrogênio, aumentando de forma expressiva o número de células em processo de divisão, e da altura de corte, definindo maior comprimento da bainha. $\mathrm{O}$ nitrogênio, ao estimular a produção de novas células, possibilita aumento na taxa de alongamento de folhas, o que pode constituir meio para mudanças no tamanho da lâmina foliar.

Mazzanti et al. (1994) apontaram correlação significativa entre $\mathrm{TA}_{\mathrm{L}} \mathrm{F}$ e comprimento de lâmina foliar $(\mathrm{r}=0,61 ; \mathrm{P}<0,001)$. Para o cultivar Mombaça foi encontrada correlação linear significativa $(\mathrm{P}<0,01)$, com $r=0,48$. Uma vez estabelecida correlação significativa entre altura ou comprimento de bainha e comprimento de lâmina, a altura de corte ou pastejo constitui importante fator na definição do tamanho final da lâmina (Grant et al., 1981; Duru \& Ducrocq, 2000a).
Tabela 2 - Médias de comprimento $(\mathrm{cm})$ de lâmina foliar do capim-Mombaça em função do suprimento de nitrogênio e das alturas de corte

Table 2 - Means of leaf lamina length $(\mathrm{cm})$ of Panicum maximum cv. Mombaça in response to nitrogen supply and cutting height

\begin{tabular}{|c|c|c|c|c|c|}
\hline \multirow[t]{2}{*}{$\begin{array}{l}\text { Altura de corte } \\
(\mathrm{cm}) \\
\text { Cutting height } \\
(\mathrm{cm})\end{array}$} & \multicolumn{4}{|c|}{$\begin{array}{c}\text { Dose de nitrogênio } \\
\left(\mathrm{mg} / \mathrm{dm}^{3}\right) \\
\text { Nitrogen level } \\
\left(\mathrm{mg} / \mathrm{dm}^{3}\right)\end{array}$} & \multirow[t]{2}{*}{$\begin{array}{c}\text { Médias } \\
\text { Means }\end{array}$} \\
\hline & 0 & 50 & 100 & 200 & \\
\hline 5 & 34,8 & 42,4 & 41,9 & 48,4 & 41,9 \\
\hline 10 & 44,5 & 49,2 & 50,8 & 46,5 & 47,7 \\
\hline 20 & 51,9 & 55,1 & 55,2 & 55,4 & 54,4 \\
\hline $\begin{array}{l}\text { Médias } \\
\text { Means }\end{array}$ & 43,7 & 48,9 & 49,3 & 50,1 & \\
\hline
\end{tabular}

\section{Número de folhas por perfilho}

Tanto o número total de folhas como o de folhas verdes foram significativamente afetados pelas doses de N (Figuras 6 e 7), sendo para a variável folhas verdes verificado o efeito adicional da altura de corte (Figura 7). O número total de folhas, de acordo com a equação ajustada, segundo as doses de 0,50, $100 \mathrm{e}$ $200 \mathrm{mg}$ de $\mathrm{N} / \mathrm{dm}^{3}$, foi, respectivamente, de 2,$9 ; 4,0$; 4,9; e 6,0 folhas por perfilho.

O número de folhas verdes aumentou linearmente com o suprimento de nitrogênio e com as alturas de corte, encontrando nas maiores doses de $\mathrm{N}$ e de altura de corte seus maiores valores.

A variação no número total de folhas, no presente estudo, apesar de não seguir o padrão demonstrado por Yang \& Matthew (1998), em relação às alturas de corte, foi bem caracterizada em relação ao efeito do suprimento do nitrogênio. Duru e Ducrocq (2000a) também verificaram expressiva significância do nitrogênio no número total de folhas, ratificando em parte os resultados aqui obtidos. Pode-se inferir que a combinação das variáveis $\mathrm{TA}_{\mathrm{P}} \mathrm{F}$ e DVF é importante como condicionante da plasticidade fenotípica das plantas. Embora o efeito do corte não tenha sido significativo em relação ao número total de folhas, este o foi em relação ao número de folhas verdes e DVF, sendo esta última variável, segundo Lemaire \& Agnusdei (1999), determinante do número de folhas do perfilho. A significância do corte em relação à 


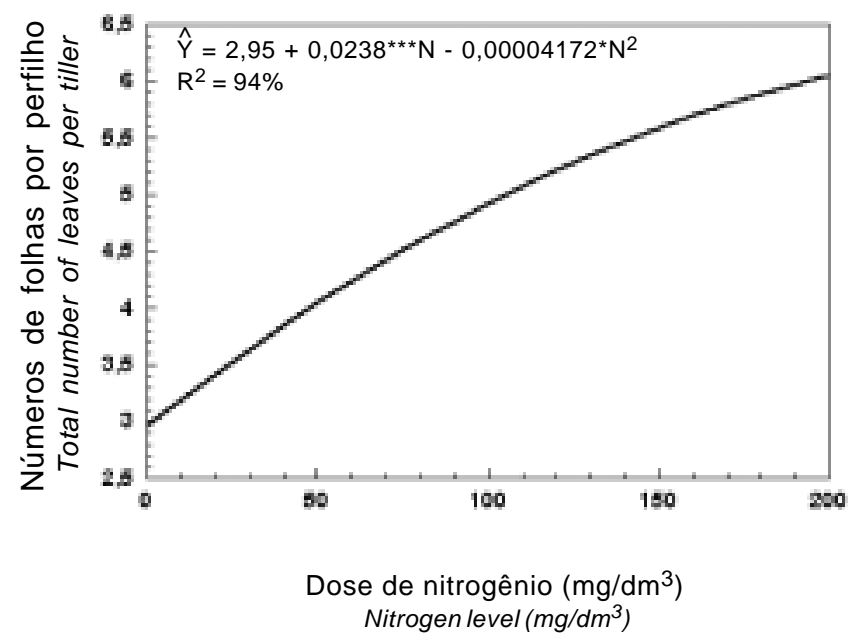

Figura 6 - Número total de folhas por perfilho de capim Mombaça em função do suprimento de $\mathrm{N}$; significativo a $1 \%\left({ }^{* * *}\right)$ e $10 \%\left(^{*}\right)$.

Figure 6 - Total number of leaves per tiller of Panicum maximum cv. Mombaça in response to nitrogen supply; significant at $1 \%\left({ }^{* *}\right)$ and $10 \%\left({ }^{*}\right)$.

DVF poderia ser, então, uma forma de a altura de corte regular o número total de folhas. Esse comportamento ressalta a importância do regime de corte na caracterização da estrutura do perfilho, mesmo quando estatisticamente não significativo na definição do número total de folhas.

Nesse contexto, o número total de folhas expressaria o potencial de assimilação de carbono, dado pelo número de folhas verdes, modificado pelo padrão na alocação de recursos para o crescimento, particularmente quando estabelecido o processo de senescência. Os dados mostram que o nitrogênio pode, simultaneamente, aumentar não só o número total de folhas, como também o número de folhas verdes. Esse comportamento foi ratificado pela baixa senescência de folhas mesmo em doses mais elevadas de nitrogênio.

Como o nitrogênio elevou a DVF, esta variável foi fundamental para o maior NFV no perfilho. O número total de folhas para uma dose de $150 \mathrm{mg}$ de $\mathrm{N} / \mathrm{dm}^{3}$ e uma altura de corte de $10 \mathrm{~cm}$ seria estimado em 5,6 folhas, valor este muito próximo (pouco acima de 5 folhas) do encontrado por Gomide (1997) em condição experimental semelhante.

\section{Número de perfilhos}

O suprimento de nitrogênio teve efeito significativo $(\mathrm{P}<0,01)$ sobre o número total de perfilhos e sobre a produção de perfilhos no período, revelando um padrão quadrático na resposta da variável, de acordo com as equações ajustadas. Não foi observada qualquer influência da altura de corte sobre o perfilhamento $(\mathrm{P}>0,10)$.

O número total de perfilhos apresentou correlação linear significativa $(\mathrm{P}<0,0001)$ com o número total de folhas $(r=0,75)$ e, conseqüentemente, com a $\mathrm{TA}_{\mathrm{P}} \mathrm{F}(\mathrm{r}=0,75)$, comportamento semelhante ao encontrado por Zarrough et al. (1984).

A $\mathrm{TA}_{\mathrm{P}} \mathrm{F}$ constitui importante determinante na taxa potencial de produção de gemas para a geração de novos perfilhos, as quais desenvolverão perfilhos em função da interação de vários outros fatores, como luz e nutrientes.

Trabalhos têm demonstrado tanto o efeito do nitrogênio (Simon \& Lemaire, 1987; Mazzanti et al., 1994) como o de regimes de corte (Grant et al., 1981) sobre o perfilhamento. A $\mathrm{TA}_{\mathrm{P}} \mathrm{F}$ realmente configura sua importância na produção de perfilhos quando as plantas formam dosséis espaçados, onde a competição por nutrientes ainda não é tão alta. Nessa condição, a taxa de perfilhamento pode ser estimada a partir da $\mathrm{TA}_{\mathrm{P}} \mathrm{F}$, caracterizando o termo "site filling", inicialmente proposto por Davies (1974). Numa condição de dosséis muito densos, o perfilhamento normalmente é inferior ao potencial dado pela $\mathrm{TA}_{\mathrm{P}} \mathrm{F}$, caracterizando o efeito de forte competição entre indivíduos por assimilados e luze definindo o conceito de "site usage" (Skinner \& Nelson, 1992).

A $\mathrm{TA}_{\mathrm{P}} \mathrm{F}$ sugere ser a ferramenta básica inicial no estabelecimento do estande, podendo ser altamente significativa, tanto em função do corte como da

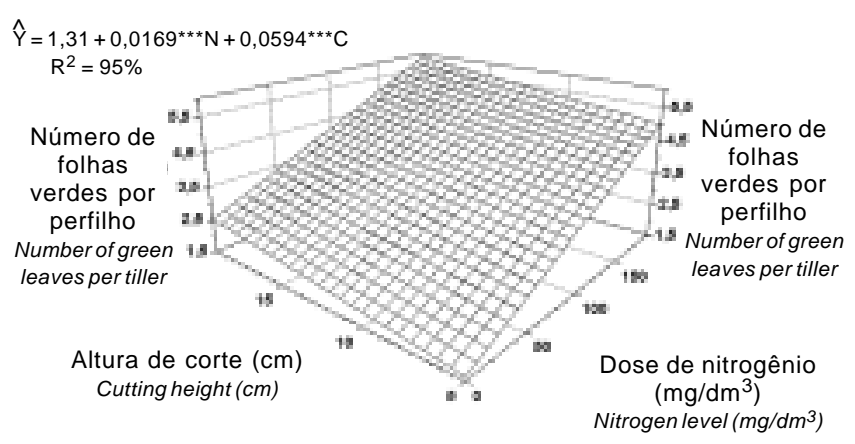

Figura 7 - Número de folhas verdes por perfilho de capim Mombaça em função do suprimento de $\mathrm{N}$ e das alturas de corte; significativo a $1 \%\left({ }^{* * *}\right)$.

Figure 7 - Number of green leaves per tiller of Panicum maximum in response to nitrogen supply and cutting height; significant at $1 \%\left({ }^{* * *}\right)$. 
aplicação de nitrogênio, ou de ambos. Considerando o corte, este fator terá sua ação estabelecida pelo encurtamento do trajeto da folha dentro do pseudocolmo, assim como pela maior penetração de luz no dossel. Em se tratando de cultivo em vasos, isso não estabeleceria uma limitação à penetração de luz para a ativação das gemas axilares, gemas estas de onde se desenvolveriam os novos perfilhos. Essa é uma possível explicação para a falta de significância estatística da altura de corte sobre a variável na condição de primeira rebrotação, como a adotada no presente experimento.

A importânciadaluz, na sua quantidade equalidade, é caracterizada mostrando que, com aumento do índice de área foliar e diminuição do perfilhamento, a $\mathrm{TA}_{\mathrm{L}} \mathrm{F}$ pode ser aumentada (Casal et al., 1985). Esse fenômeno pode ser interpretado como uma adaptação de plantas individuais à severa competição por luz em dosséis muito fechados, o que determina a alocação de carboidratos preferencialmente para o alongamento de folhas.

Quanto ao nitrogênio, foi visível seu efeito sobre o número total de perfilhos (Figura 8), principalmente sobre o número de perfilhos produzidos (Figura 9) no período de rebrotação.

Obtiveram-se, em relação às doses de $0,50,100$ e $200 \mathrm{mg}$ de $\mathrm{N} / \mathrm{dm}^{3}$, levando-se em conta a equação

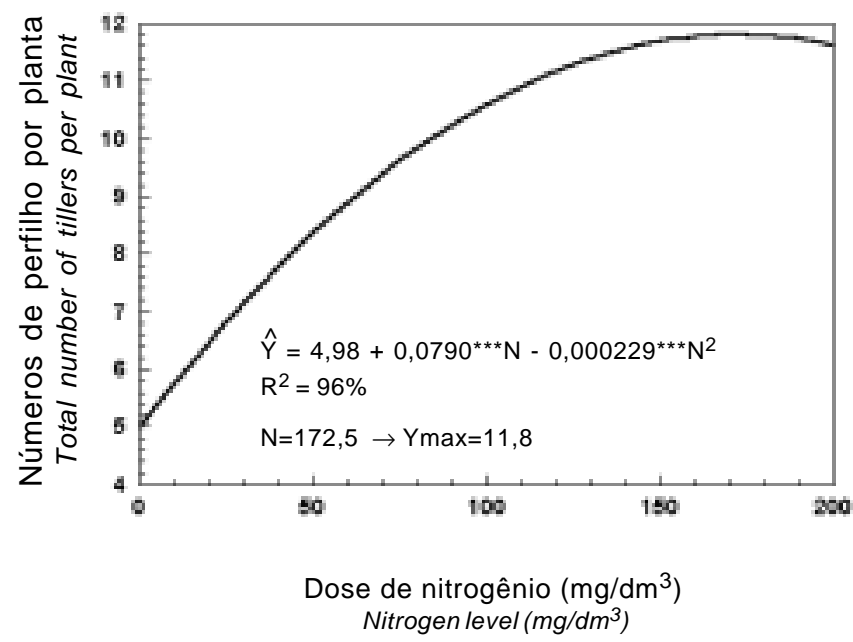

Figura 8 - Número total de perfilhos por planta de capim Mombaça em função do suprimento de $\mathrm{N}$; significativo a $1 \%\left({ }^{* * *}\right)$.

Figure 8 - Total number of tillers per plant, in Panicum maximum cv. Mombaça, in response to nitrogen supply; significant at $1 \%\left({ }^{* * *}\right)$. ajustada, médias de total de perfilhos e de perfilhos produzidos iguais a: 5(1), 8(4), 10(6) e 12(7) perfilhos por planta.

A taxa de alongamento de folhas apresentou correlação (linear) significativa $(r=0,80 ; \mathrm{P}<0,0001)$ com a produção forrageira. Ao contrário do encontrado por Zarrough et al. (1984), não foi verificada correlação negativa entre $\mathrm{TA}_{\mathrm{L}} \mathrm{F}$ e número total de perfilhos. Como no presente estudo houve correlação positiva entre $\mathrm{TA}_{\mathrm{P}} \mathrm{F}$ e $\mathrm{TA}_{\mathrm{L}} \mathrm{F}$ e a $\mathrm{TA}_{\mathrm{P}} \mathrm{F}$ seguiu a mesma correlação com o número total de perfilhos, esperava-se, como aconteceu, que o perfilhamento não seguisse a proposição de Zarrough et al. (1984).

Mazzanti et al. (1994) verificaram que a adubação nitrogenada elevou o número de perfilhos em $22 \%$ quando o suprimento de $\mathrm{N}$ passou de 45 para $90 \mathrm{~kg} / \mathrm{ha}$, aplicados a cada 45 dias. No mesmo experimento foi constatado um aumento de $39 \%$ no crescimento da planta forrageira, como conseqüência de um aumento de $21 \%$ na densidade populacional de perfilhos e de $23 \%$ na $\mathrm{TA}_{\mathrm{L}} \mathrm{F}$. Esse comportamento deve ser levado em conta ao se definir o tipo de manejo a ser adotado na pastagem. A redução da $\mathrm{TA}_{\mathrm{L}} \mathrm{F}$ de perfilhos mantidos sob menor área foliar por meio de pastejo sob lotação contínua explicaria a pequena resposta da $\mathrm{TA}_{\mathrm{L}} \mathrm{F}$ à fertilização nitrogenada

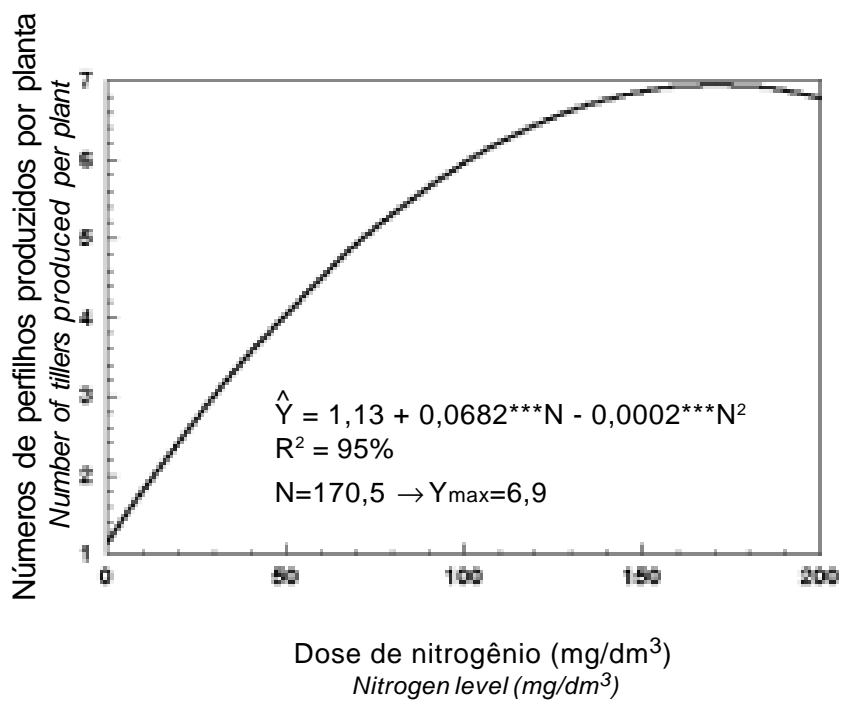

Figura 9 - Número de perfilhos por planta de capim Mombaça produzidos no período de rebrotação em função das doses de $\mathrm{N}$; significativo a $1 \%\left({ }^{* * *}\right)$.

Figure 9 - Number of tillers per plant of Panicum maximum cv. Mombaça produced on period of regrowth in response to nitrogen supply, significant at $1 \%\left({ }^{* * *}\right)$.

R. Bras. Zootec., v.31, n.5, p.1890-1900, 2002 
quando comparada à $\mathrm{TA}_{\mathrm{L}} \mathrm{F}$ em condição de pastejo sob lotação rotacionada (Gastal \& Lemaire, 1988). A importância da $\mathrm{TA}_{\mathrm{L}} \mathrm{F}$ como um componente da resposta de crescimento à adubação nitrogenada parece ser menor em pastejo sob lotação contínua que sob lotação rotacionada, sendo parcialmente compensada pelo efeito do nitrogênio sobre a densidade populacional de perfilhos (Mazzanti et al., 1994). Em virtude da correlação verificada entre $\mathrm{TA}_{\mathrm{P}} \mathrm{F}, \mathrm{TA}_{\mathrm{L}} \mathrm{F}$ e número de perfilhos, pode-se observar que em determinadas práticas de manejo é possível quebrar o equilíbrio típico de uma comunidade de plantas cultivadas, cabendo ao manejador identificar as peças-chave no controle do crescimento para otimizar a produção forrageira.

O perfilhamento em gramíneas constitui característica estrutural fortemente influenciada por uma larga combinação de fatores nutricionais, ambientais e de manejo, os quais definem as características morfogênicas, que, por sua vez, são determinantes para a resposta morfogênica das plantas forrageiras.

\section{Conclusões}

Os resultados obtidos mostraram que, em relação às variáveis morfogênicas, as taxas de aparecimento e alongamento de folhas e o filocrono foram bastante significativos em resposta ao suprimento de $\mathrm{N}$, mas não em relação às diferentes alturas de corte. A duração de vida da folha, diferentemente do que aconteceu com as demais variáveis morfogênicas, foi também caracterizada pelas alturas de corte, mostrando que a persistência de lâminas foliares no perfilho pode ser aumentada de forma bastante expressiva através de maiores alturas. Em relação a essa variável, o efeito da altura de corte foi mais evidente que o suprimento de nitrogênio, apesar da significância de ambos os fatores.

Houve correlação linear significativa entre $\mathrm{TA}_{\mathrm{P}} \mathrm{F}$ e $\mathrm{TA}_{\mathrm{L}} \mathrm{F}(\mathrm{r}=0,94 ; \mathrm{P}<0,0001)$. Quanto ao número de folhas verdes, o principal agente transformador foi o nitrogênio. A observação desse comportamento está bem associada à DVF, particularmente nas menores alturas de corte, como verificado para 5 e $10 \mathrm{~cm}$. A importância do $\mathrm{N}$ define não só a $\mathrm{TA}_{\mathrm{P}} \mathrm{F}$ como também a $\mathrm{TA}_{\mathrm{L}} \mathrm{F}$ como componentes fundamentais na plasticidade fenotípica da planta. Isso é válido tanto em relação à planta como indivíduo, através do número de folhas e duração do alongamento, como também em termos de comunidade de plantas, pela geração de novos perfilhos.

\section{Literatura Citada}

BONHOMME, R. Bases and limits to using "degree.day" units. European Journal of Agronomy, v.13, p.1-10, 2000.

CASAL, J. J.; DEREGIBUS, V.A.; SANCHEZ, R.A. Variation on tiller dynamics and morphology in Lolium multiflorum Lam. Vegetative and reproductive plants as affected by differences in red/far-red irradiation. Annals of Botany, v.56, p.553-559, 1985.

CRUZ, P.; BOVAL, M. Effect of nitrogen on some traits of temperate and tropical perennial forage grasses. In: GRASSLAND ECOPHYSIOLOGY AND GRAZING ECOLOGY, 1999, Curitiba. Proceedings ... Curitiba: 1999. p.134-150.

DAVIES, A. Leaf tissue remaining after cutting and regrowth in perennial ryegrass. Journal of Agricultural Science, v.82, p.165-172, 1974.

DURU, M.; DUCROCQ, H. Growth and senescence of the successive leaves on a Cocksfoot tiller. Effect of nitrogen and cutting regime. Annals of Botany, v.85, p.645-653, 2000a.

DURU, M.; DUCROCQ, H. Growth and senescence of the successive grass leaves on a tiller. Ontogenic development and effect of temperature. Annals of Botany, v.85, p.635643, 2000b.

GASTAL, F.; BELANGER, G.; LEMAIRE, G. A model of the leaf extension rate of tall fescue in response to nitrogen and temperature. Annals of Botany, v.70, p.437-442, 1992.

GASTAL, F.; LEMAIRE, G. Study of a tall fescue sward growth under nitrogen deficiency conditions. In: GENERAL MEETING OF THE EUROPEAN GRASSLAND FEDERATION, 12., 1988, Dublin. Proceedings... Dublin: 1988. p.323-327.

GASTAL, F.; NELSON, C.J. Nitrogen use within the growing leaf blade of tall fescue. Plant Physiology, v.105, p.191-197, 1994.

GOMIDE, C.A. Morfogênese e análise de crescimento de cultivares de Panicum maximum (Jacq.). Viçosa, MG: Universidade Federal de Viçosa, 1997. 53p. Dissertação (Mestrado em Zootecnia) - Universidade Federal de Viçosa, 1997.

GRANT, S.A.; BARTHRAM, G.T.; TORVEL, L. Components of regrowth in grazed and cut Lolium perenne swards. Grass and Forage Science, v.36, p.155-168, 1981.

HODGSON, J. Grazing management: science into practice. New York: John Wiley \& Sons, 1990. 203p.

LANGER, R.H.M. How grasses grow. 2.ed. London: Edward Arnold, 1974. 60p.

LEMAIRE, G.; CHAPMAN, D. Tissue flows in grazed plant communities. In: HODGSON, J.; ILLIUS, A.W. (Eds.) The ecology and management of grazing systems. Wallingford: Cab International, 1996. p.3-36.

LEMAIRE, G.; AGNUSDEI, M. Leaf tissue turn-over and efficiency of herbage utilization. In: GRASSLAND ECOPHYSIOLOGY AND GRAZING ECOLOGY, 1999, Curitiba. Proceedings... Curitiba: 1999. p.134-150.

LEMAIRE, G.; CULLETON, N. Effects of nitrogen applied after the last cut in autumn on a tall fescue sward. II. Uptake and recycling of nitrogen in the sward during winter. Agronomy, v.9, p.241-249, 1989.

LONGNECKER, N.; KIRBY, E.J.M.; ROBSON, A. Leaf emergence, tiller growth, and apical development of nitrogendeficient spring wheat. Crop Science, v.33, p.154-160, 1993.

MAZZANTI, A.; LEMAIRE, G.; GASTAL, F. The effect of nitrogen fertilization upon the herbage production of tall

R. Bras. Zootec., v.31, n.5, p.1890-1900, 2002 
fescue swards continuously grazed with sheep. 1. Herbage growth dynamics. Grass and Forage Science, v.49, p.111-120, 1994.

OMETTO, J.C. Bioclimatologia vegetal. São Paulo: Ceres, 1981. 440p.

SAS INSTITUTE. SAS/STAT User's Guide. 4.ed. version 6. Cary: 1990. 943p.

SIMON, J. C.; LEMAIRE, G. Tillering and leaf area index in grasses in the vegetative phase. Grass and Forage Science, v.42, p.373-380, 1987.

SKINNER, R.H.; NELSON, C.J. Estimation of potential tiller production and site usage during tall fescue canopy development. Annals of Botany, v.70, p.493-499, 1992.

SKINNER, R.H.; NELSON, C.J. Elongation of the grass leaf and its relationship to the phyllochron. Crop Science, v.35, n.1, p.4-10, 1995.

THOMAS, H. Analysis of the nitrogen response of leaf extension in Lolium temulentum seedlings. Annals of Botany, v.51, p.363-371, 1983.

VOLENEC, J.J.; NELSON, C.J. Responses of tall fescue leaf meristems to $\mathrm{N}$ fertilization and harvest frequency. Crop Science, v.23, p.720-724, 1983.
VOLENEC, J.J.; NELSON, C.J. Carbohydrate metabolism in leaf meristems of tall fescue. II. Relationship to leaf elongation rates modified by nitrogen fertilization. Plant Physiology, v.74, p.595-600, 1984.

WILSON, R.E.; LAIDLAW, A.S. The role of the sheath tube in the development of expanding leaves in perennial ryegrass. Annals of Applied Biology, v.106, p.385-391, 1985.

YANG, J.Z.; MATTHEW, C. Tiller axis observations for Ryegrass (Lolium perenne) and tall fescue (Festuca arundinacea): number of active phytomers, probability of tiller appearance, and frequency of root appearance per phytomer for three cutting heights. New Zealand Journal of Agricultural Research, v.41, p.11-17, 1998.

ZARROUGH, K.M.; NELSON, C.J.; SLEPER, D.A. Interrelationships between rates of leaf appearance and tillering in selected tall fescue populations. Crop Science, v.24, p.565-569, 1984.

Recebido em: 02/10/01

Aceito em: 11/04/02 